\title{
Making a Case for Technology in Academia
}

\section{Kathrin Dodds, Donell Callender, and Cynthia Henry}

\begin{abstract}
Interested in connecting users with the latest resources aimed at advancing intellectual inquiry and discovery, researchers from Texas Tech University Libraries decided to embark on a study to explore the practicality of the latest technology, the iPad, within the varying functions of academia. Using an online survey and focus groups, the researchers sought to investigate how students and faculty felt the iPad might be used in teaching and learning, as well as research. This article describes the process the researchers used to obtain iPads for research and how they explored their use in an academic setting.
\end{abstract}

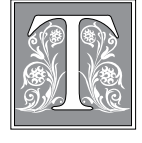

he Texas Tech University Libraries connects its users with the latest resources to advance intellectual inquiry and discovery as stated in its mission. Texas Tech University Libraries is always looking for new ways to teach, to research and to promote learning, whether it is through new practices, methods or technologies. With the release of the Apple iPad, there was a lot of curiosity and speculation on its uses within the academic environment. By experimenting with this new device, the research team developed a study seeking to investigate how the iPad is different from other technologies and how it can make a difference in the way academia teaches and learns. With this in mind, the researchers decided to explore the practicality of the iPad within the varying functions of higher education, especially in the classroom, for teaching and learn- ing, and in research by conducting a survey and focus groups of iPad users and novices. Using the knowledge gathered through these methods, the researchers hope to make a case in favor of the use of technology in academia, specifically the use of the iPad.

\section{Literature Review}

According to the Chronicle of Higher Education - The Digital Campus, faculty members reported feeling burdened by having to keep up with the new technology and felt unrewarded for using the technology while teaching. Despite this fact, the use of and the dynamically changing landscape of technology will influence the academic environment. There is a plethora of literature all pointing toward the looming horizon of how tablet technology will affect the classroom. In the article "Is Education

Kathrin Dodds is Director of Business Development E Research, Perman Technical Search Group, e-mail: coppertopmls@gmail.com; Donell Callender is Associate Librarian for Education at Texas Tech University, e-mail: donell.callender@ttu.edu; and Cynthia Henry is Associate Librarian for Human Sciences at Texas Tech University, e-mail: cynthia.henry@ttu.edu. (C) 2014 Kathrin Dodds, Donell Callender, and Cynthia Henry, Attribution-NonCommercial (http://creativecommons.org/licenses/by-nc/3.0/) CC BY-NC 
1.0 Ready for Web 2.0 Students," John Thompson states: "students will soon arrive at college expecting a transformative form of education." ${ }^{11}$ Students who have been multitasking, using a mobile device on a daily basis, and comfortable with applications (commonly referred to as apps) pushing information to and from the web will have a hard time adjusting to the traditional standard lecture. Academia needs to be able to incorporate this new technology into the classroom. Thompson further adds, "It will not be easy, but the next generation will create new models of scholarly publishing and learning, regardless of whether we choose to participate." 2 By using the new devices that allow instant on, a professor could include activities such as posting and reviewing comments from students in real time that would have a greater impact on the students. Thompson goes on to say, "Student motivation may increase when their writing can be read by thousands instead of a handful." ${ }^{3}$ This will engage students to be more hands-on in their education. Instead of just receiving information, students should be able to analyze and synthesize the material discussed in class. Now, with the option to get feedback in the moment not only from professors but from classmates as well, the process seems to be more organic. The curriculum could include these additional nontraditional activities. The devices seem to speed up the learning process, as stated in the Oklahoma State University iPad study: "Among the enhancements noticed by both professors and students was an increase to the pace of the course, reaching traditional benchmarks sometimes weeks in advance." 4

Further strengthening the idea that technology can aid the learning process originated in an informal study by University of Wisconsin, Rock County Professor John Fons. ${ }^{5}$ After receiving numerous requests for electronic copies of lectures and noticing the prevalence of laptop computers in the classroom, Fons attempted to adopt his students' technology-driven lifestyle by trying a year without paper. Fons distributed tablet PCs to students and found almost immediately that, when he used the devices in the classroom and labs, the classroom itself became more student-centered and dynamic. After a year of conducting lectures and assignments electronically, both he and his students concluded that using the devices helped them all to keep organized throughout the year.

In Technology and YOU, Elizabeth Marcoux further opines how teacher librarians can integrate technology into practice. Discussing the role that smartphones, tablet PCs, and other portable computing devices should play in the classroom, Marcoux says that "educators have the responsibility to determine how best to use various technologies, in what capacities, and also when not to use them." ${ }^{\prime \prime}$ Issues seem to fall primarily in the lack of teachers' technology competencies. Students are more comfortable with and use technology more than ever before. However, it should be the teachers providing leadership in the use of technology in teaching and learning.

The University of Ontario's Institute of Technology conducted additional research into the use of tablets in academia by issuing tablet PCs to thirty-one university students in a 2005-2006 academic year study. "The primary research problem driving the University of Ontario project revolved around the student perceptions of the benefits of tablet PCs to provide opportunities to restructure their learning experiences."7 This study did not include the iPad; but, according to the study's findings, the iPad's future use in the classroom can be "informed by the results of this study." ${ }^{8}$ The study found that ubiquitous computing is a given but that it provides both students and faculty equal footing as "both will have access to the same resources." ${ }^{\prime 9}$ However, this does not address the issue of comfort with technology. The overall conclusion suggests, "as iPads and other touch interface-driven devices are introduced into the classroom 
of the future, instructors and students should be wary of continuing to expect the devices to bring about a classroom transformation." ${ }^{10}$ Van Oostveen also suggested that students, who are motivated to learn, would succeed "regardless of the availability or access to technology" but warned, "many students may resist a move to a more active, self-directed style of learning with technology, if this mode conflicts with past learning experiences." ${ }^{11}$

In the article, Enhancing Student Performance, Amelito Enriquez, a professor of Engineering and Mathematics at Canada College, conducted a study on the traditional tablet PC, but made a pertinent statement in their implications of iPads and similar technology. "As there is an infusion into the classroom of technology, mathematics, science and engineering faculty in all levels of education should consider using tablet PCs over laptop and desktop computers in the classroom."12 This includes faculty as well as students. Faculty might be a little more resistant. “Networked tablets PCs enable students and faculty to analyze problems, collect data, take notes, and combine handwritten and other electronic class materials."13 There is now a true opportunity for synchronized learning, both in and out of the classroom, and all at a digital pace. "They also offer the flexibility to write and manipulate mathematical formulas, draw sketches, and add ink annotations when solving ad-analyzing problems. These benefits should be weighed against the additional cost of a few hundred dollars for a tablet PC compared with a regular laptop computer." ${ }^{14}$ Considering all the advantages of the tablet PCs and now the tablets like iPad, along with a reasonable price tag, this author states that use in education and the classroom is a given.

Hawkes at Dakota State University, Madison, along with Claver Hategekimana at Wenatchee Valley College conducted a study of the impact of mobile computing and student assessment outcomes determined that with new technology comes new terminology:
Several terms are associated with the idea of mobile computing including one-to-one computing, wireless computing, and m-learning. These descriptors attempt to give identity to the idea that every student has full-time access to a computer, the Internet, and other resources that allow them to work anytime, anywhere with the technology. What is universally accepted about mobile computing is that it reflects more than having a computer. The mobile learning environment provides student access to a variety of digital devices and services. ${ }^{15}$

This article discusses the push behind mobile learning, or the new term mlearning. The authors state that many are making the push to mobile learning and ask why institutions are investing in this push. Hawkes paraphrases from a Stanford Research Institute (SRI) report from 2002 to answer the question:

1. to improve academic success,

2. to increase equity of access of digital resources,

3. to increase regional economic competitiveness by preparing students to effectively use technology in the workplace; and

4. to effect a transformation in the quality of instruction. ${ }^{16}$

Hawkes also discusses the concerns that come with technology in the classroom; specifically, the support, or lack thereof, for policies and people that make the adoption of networked things such as e-mail, instant messaging, and Internet browsing difficult.

A great deal of the literature seems to suggest that students are comfortable with all types of mobile technology and want its use in the classroom. Many faculty members, although curious about technology, are not sure how best to incorporate their use into teaching and learning. Since the release of the first gen- 
eration iPad in 2010, several colleges and universities began pilot programs to test the effectiveness of the device for teaching and learning. Among them, Pepperdine University's iPad Research Initiative consisted of three areas of study: classroom observations, surveys, and focus groups. Their "preliminary findings suggest that students have found value in using the iPad because of its ease of use, mobility and the vast variety of apps available."17 Hong Kha, a Pepperdine professor and part of the iPad research team says of students, "Not only do they need to understand the capacities and strengths of the device; they also need to be able to identify specific apps that are relevant to their subject matter and to the specific learning activities of their course."18 The Pepperdine study further concluded that "to bring the iPad into the classroom in an effective way, you need to provide faculty development support to assist the instructor in defining a specific pedagogical objective or challenge that the iPad can be used to address, and identifying the app and the use of it in a learning activity." ${ }^{19}$ Other studies in 2010 included one conducted by the University of Houston's School of Communication and the Education Technology and University Outreach organization. Their joint project focused on researching the impact of "anytime, anywhere" learning by creating an application for an Information and Communication Technologies course. ${ }^{20}$ The application contains learning modules with video lectures, textbook material, presentations, tutorials and simulations. The goal of the study was to obtain feedback for the university's M-Learning Program, which focuses on helping faculty integrate mobile technologies into their curriculum. The Brooklyn campus of Long Island University study expanded on a successful pilot in which all freshmen received an iPad. In preparation for the first phase of the project, the campus improved its wireless infrastructure and added additional access points. The initiative was designed to "help students connect with classmates, faculty members and advisers; organize, store and share files, assignments and presentations, help students access their academic and financial aid records; download digital books; take notes in class and conduct research online." 21

In the article Is the iPad Ready to Replace the Printed Textbook? Schaffhauser mentions several iPad pilot projects going on including the Abilene Christian University project, where every student was required to purchase iPods and iPhones, and their continued project with support from AT\&T for a 1.8-million-dollar grant for a three-part mobile learning initiative. Schaffhauser feels that the iPad is not yet ready, but getting there. Two things must happen: The amount of digital textbooks available must increase, and the cost per item must go down. Schaffhauser pitched an interesting thought. With such mediarich environments, why does a textbook have to be just a book? Schaffhauser suggests that digital textbooks have a high degree of interactive capability. ${ }^{22}$

Other universities who conducted pilot studies in 2010 include West Chester University (WCU) and Reed College. As West Chester University noted in an article in the Pottstown, PA, Mercury on September 30, 2010, "the overall goal of the WCU study was to explore the viability and usability of the tablet device as a tool for teaching, learning, and scholarship." ${ }^{23}$ In the study, a group of faculty across all five WCU colleges participated on the continuation of earlier eReader research - though the questions took into consideration iPad devices and their increased capabilities. For the spring/ summer 2011 semesters, they put a call out to their faculty to submit proposals on how they wished to experiment with or apply iPad or other tablet technology in their teaching. Interested faculty detailed how they would use the device pedagogically. College participants in the first round, as reported in April 2011, viewed iPads positively. They found it "useful in class preparation.... Its portability, size 
and battery life enabled faculty to take it anywhere, allowing them to prepare for class as efficiently as possible, even while traveling." 24 "For classes involving movement-i.e. science labs and dance studies, they found that the portability and touch controls made it ideal for students to access lab materials, view videos, run simulations and perform calculations." ${ }^{25}$ The Reed College faculty participants listed shortcomings that need dealing with before "it is to be as useful in the classroom as a laptop or desktop computer. Those shortcomings include file management, input methods and content creation, software availability along with training and support." ${ }^{26}$ Reed College is continuing their program and will have further reports available in December 2011.

Studies include Buena Vista University, who plans to give every one of their students $(1,100)$ at their Storm Lake, Iowa, campus an Apple iPad 2 along with a laptop computer in fall 2011. Their spring 2011 pilot "affirmed that the iPad is a simple, versatile and easy to use device." ${ }^{27}$ Another aspect of the project is that students will choose whether to use printed or digital textbooks. Professors, on the other hand, will choose how to use the technology in their courses. One instructor involved in the initial project found that iPad usage helped her collaborate and interact with each other and the texts.

\section{Methodology}

The idea for this project began in July 2010 when the researchers wanted to investigate the new iPad technology and its uses in the classroom. Initially, searches for grants to provide funding for three devices were investigated. When the opportunity to receive internal funding from the Texas Tech University Libraries arose, the researchers wrote a proposal in September of 2010 and soon received funding that would provide for seven iPads. With funding secured, work started with the Texas Tech University Institutional Review Board (IRB). The
IRB is the office on campus that oversees any research that would involve human subjects. The researchers developed an outline of the project from beginning to end to submit to the IRB for approval.

\section{Survey}

Since the Texas Tech University Libraries connects its users with the latest resources to advance intellectual inquiry and discovery, the researchers wanted to gauge the perceptions and use of the Apple iPad. During the first meeting after receiving the internal grant, the researchers discussed the parameters for the research. Questions sprang to mind: Who is the target audience for the research? Did the researchers want to look at faculty, students, or both? How would technology influence the classroom, research, or both? Discussion led to which populations to cover in the study and identified four sets: students, faculty, novice users, and expert users. As the researchers began answering these questions, the outline for the project developed.

It was determined that the best way to gather initial information on iPad use and perception is by online survey. With the parameters in mind, the researchers developed the questions surrounding the populations that clearly had a stake in technology incorporated on campus. The survey instrument was constructed in such a way that data could be collected about how students and faculty currently use or think they would use the iPad in the classroom and for research. The researchers wanted to keep the survey short and simple, while obtaining information that would guide the focus groups. Using both qualitative (open-ended) questions and quantitative questions (forced choice); this anonymous survey collected data from student and faculty respondents of Texas Tech University. Directing the development of questions was the desire to find out what kind of experience respondents had-if any-with the iPad. The qualitative, open-ended questions allowed users to insert their own thoughts, 
allowing further opportunities to enrich the research question. The quantitative questions provided useful statistical information needed to strengthen research assumptions. In addition, the researchers wanted to look at how both tech-savvy and non-tech-savvy populations of faculty and students would relate or adapt to the idea of incorporating technology in the classroom and in their research.

After designing the survey, the researchers posted the survey on SurveyMonkey. The researchers decided to use SurveyMonkey because Texas Tech University Libraries has an institutional subscription. Recruitment of respondents took place via university announcements, e-mail through subject librarians to their departments, and a news story on the Texas Tech University Libraries website. The survey was open during the period from February 9, 2011, to April 18, 2011. A large voluntary sample of over 200 faculty and students responded to the survey. The last question of the survey asked participants to leave contact information if they would like to participate in a follow-up for this study.

\section{Focus Group}

As the Texas Tech University Institutional Review Board application developed for the project, the researchers began identifying the parameters for the focus groups. Each focus group would not be more than eight people so that everyone who participated would have ample time and opportunity to share their thoughts. Thus, the number of focus groups grew from the number of survey respondents who volunteered to participate in the focus groups from the survey. Next, the researchers discussed the makeup of the focus groups. Should both students and faculty be included in the same focus group? How should attendees be categorized - with only novice users or expert users of iPads? Alternatively, did these populations need to be in separate groups so that each population could speak freely? After much deliberation, the organization of the focus groups developed with students and faculty as well as novice and expert users in the same focus group. The expectation was that there would be some organic interaction among the different population sets. By setting up the focus groups in this way, the focus group attendees would help one another learn how to use the device as a study tool or as a teaching tool, but also how to make the tool work for each of them in their individual research.

The researchers decided that, since both novice and experienced users were attending each focus group, there needed to be some guided tasks to set a minimum level of interaction with the iPad. The researchers developed a sheet with three tasks listed for the participants to complete at the beginning of the focus group. The tasks were to send an e-mail using the web, to find and play a YouTube video, and to use the search function on the iPad.

Finally, in the last phase of the focus group planning, the researchers took time to think about how to conduct the focus groups. The researchers looked at how group dynamics would influence the discussion in the focus groups and tried to structure them in a very organic way. Provided to all the participants, at the beginning of every focus group, was an information sheet that stated the purpose of the research and covered confidentiality. Deciding to provide light refreshments during the focus group helped relax participants and put them at ease as conversation customarily flows easily when people are eating. In addition, nametags provided to the participants allowed each person to feel comfortable addressing one another by name even though the focus group participants did not know one another. Also, permitting the focus group members to lead the discussion at different times helped the natural flow of conversation.

In March and April of 2011, the researchers held four focus groups. Each group met for an hour and a half. A moderator greeted the participants as they ar- 
rived. Each participant needed to fill out a form for the raffle, put on a nametag, and to look over the information sheet in front of him or her. At this time, participants were also encouraged to partake of the snacks and beverages provided. Once everyone had taken a seat, the moderators would turn on the recorder and begin the focus group. Each group started with everyone looking over the information sheet and then each person completed the three tasks on the iPad. The moderators allowed enough time for participants to complete the tasks without feeling rushed, as the moderators wanted participants to feel comfortable using the device. Next, the moderators started asking questions from the question sheet and discussion followed. Each focus group was a little different, which led the conversations into different areas. The moderators would allow for different topics related to the study to develop naturally; however, if the conversation moved too far off topic, the researchers would steer the conversation back to the iPad functionality. At the end of each focus group, the moderators would ask if there were any other comments anyone wanted to add, thanked the participants for coming, and again encouraged participants to partake of the snacks provided. This concluded the focus groups data collection.

\section{Findings}

\section{Survey}

Those choosing to respond to the iPad survey used the SurveyMonkey link through the various recruitment methods described previously. Of the 219 initial survey respondents, 148 were students; the remaining 71 classified themselves as faculty. Of the total respondents, $127 \mathrm{had}$ previously used an Apple iPad when they answered the survey.

When asked what they see as potential uses of the iPad in the classroom - with four named uses (eBooks, referencing web pages, educational apps, and note taking) and the option to specify their own -175 respondents see the use of eB-

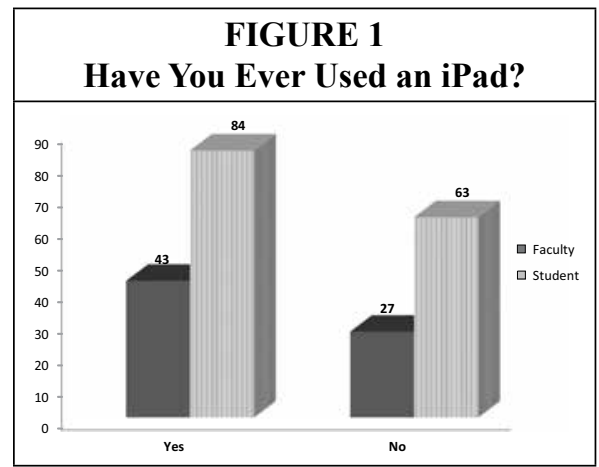

ooks as having the biggest potential use of the iPad in the classroom. Referencing web pages during lectures was the second most chosen potential use, with 168 respondents agreeing with this use. Of the respondents answering this question, 161 felt that the use of educational apps was a strong potential use in the classroom, 153 respondents would use the iPad for taking notes in class, and 57 respondents who answered the question specified other uses.

Some of the responses given for the "other" category included:

- Interactive or educational applications

- The ability to write papers

- Posting of podcasts, videos, and lecture materials

- Cooperative in-class use

- Studying anatomical models of the human body

- Accessing journal articles

- Recording of lectures

As you can see below from the selected comments of the respondents, there is a wide range of how creative faculty could use this new technology in their classrooms:

- "Develop critical analysis skills through class-wide interaction in written and graphic expression."

- "Interactive lectures with case studies, and video."

- "Group discussion. There is a textbook app that allows folks on the same network to annotate the same text, allowing for discussion." 


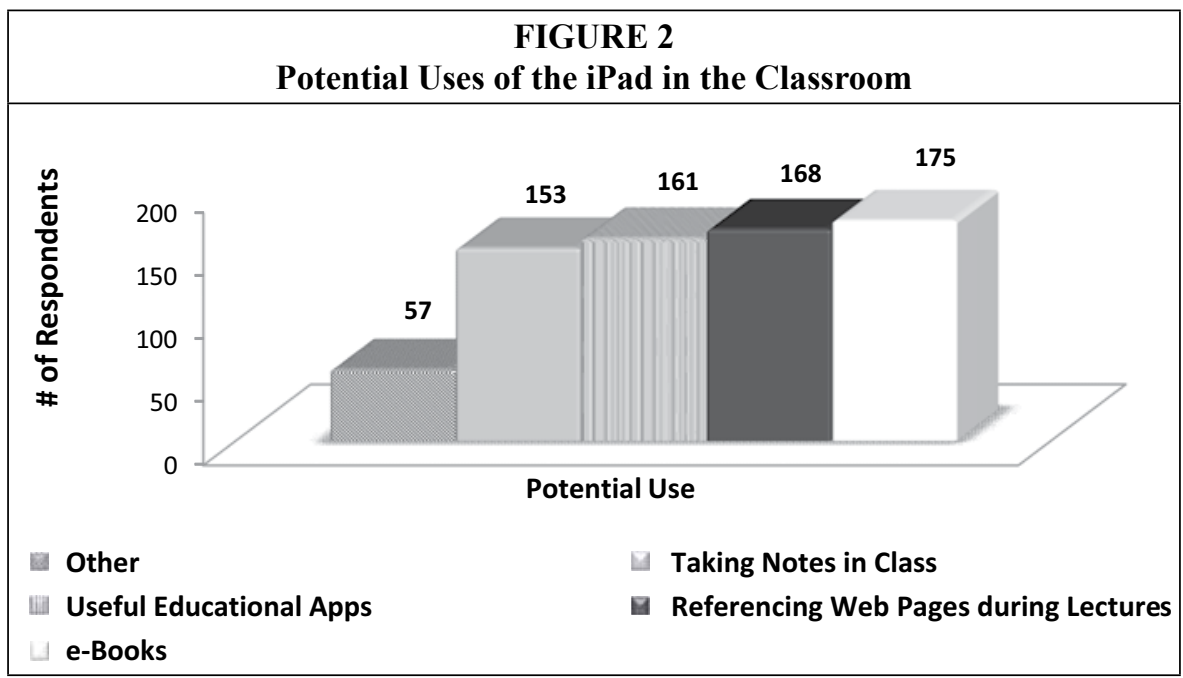

- "Recording verbal notes on student papers."

- "Real-time web recognition and web participation with external resources/individuals."

- "In class/out of class discussion and involvement."

- "Quickly looking up concepts mentioned in class that you do not understand. This will help students from falling too far behind during lecture and will enable the professor to continue his lecture without too many interruptions for basic questions."
- $\quad$ "Perhaps real-time polling during a lesson using a tool such as polleverywhere.com; when available, use Blackboard or other LMS; use other Web 2.0 collaboration tools in real-time during class."

Students are also excited to see the iPad and tablet technology incorporated into the classroom:

- "Perhaps taking video or audio recordings of the lecture if allowed by the instructor."

- "In large classrooms, maybe for dialogue or a conversation or asking questions of the professor."

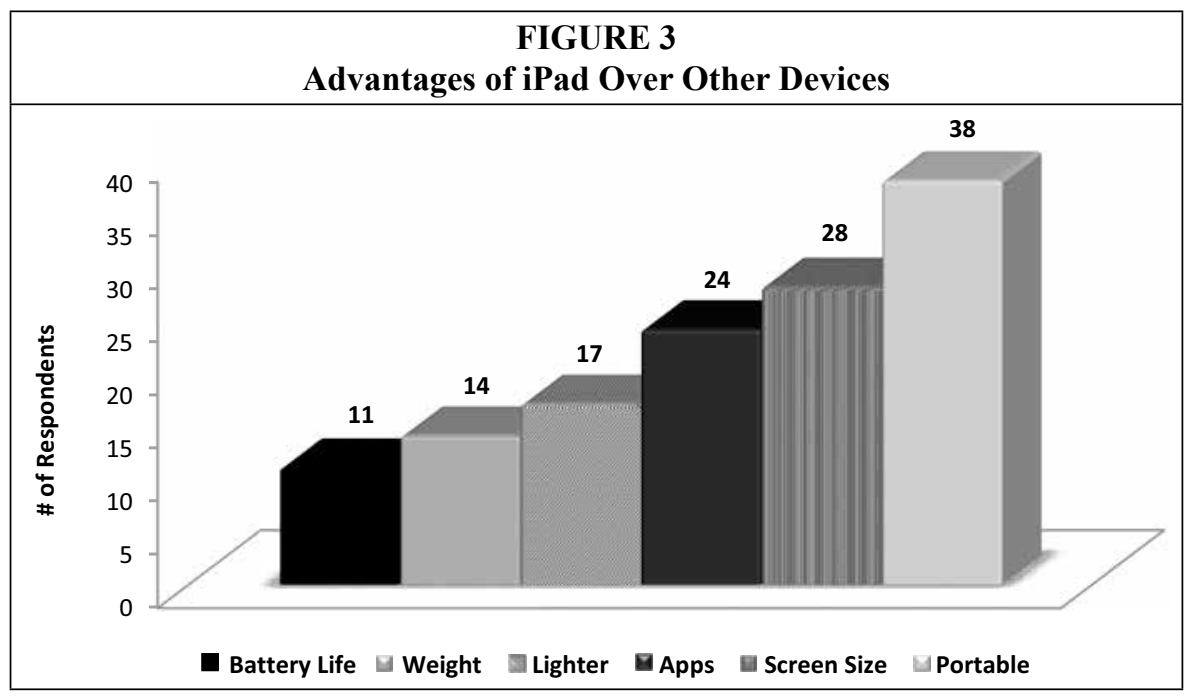


- “The ability to have documents open in front of you so you can see diagrams more easily."

Respondents saw many potential advantages of an iPad in the classroom over other devices such as a laptop, netbook, or Smartphone. Some of the advantages mentioned included:

- Weighing less than two pounds means students can easily place the device in their backpack and tote it between classes

- It immediately "boots up" when the user needs to use it

- The battery life allows users to have it with them all day without recharging

- $\quad$ Screen display size was mentioned numerous times

- The plethora of applications available

Comments from respondents further demonstrate the data:

- "Size. If I need to manipulate an image ... (spin, turn, and zoom in/ out) this would be much easier to do using the iPad over my iPhone or iTouch."

- "Bigger than my smartphone, smaller than my netbook, runs on the campus network."

- "Lighter, easier to carry, doesn't create a physical barrier between the student and the instructor, is more intuitive."

- "The remarkable touch-screen capabilities paired with a practically full-sized touch-screen keyboard make the iPad an amazing study tool."

- "Portability, reduction of sound due to lack of keyboard, more accessibility to educational apps."

- "It is easier to use on a small desk than a laptop is, it is easier to use an iPad specifically for note taking or for a specific task, where it is easy to get distracted with a laptop."

- "The iPad provides the synthesis of all smart devices. Its size and mobility allows groups or individual activities with more visual and tactile accessibility."

- $\quad$ "There are so many helpful apps available on the iPad. It functions as a smartphone and laptop combined."

- "The iPad is small and lightweight, it uses less energy than laptops and netbooks, and it is compatible with other iOS devices and apps."

- "Battery life is long (so no tripping over cords), boots up instantly, large enough to see but does not take up a lot of space."

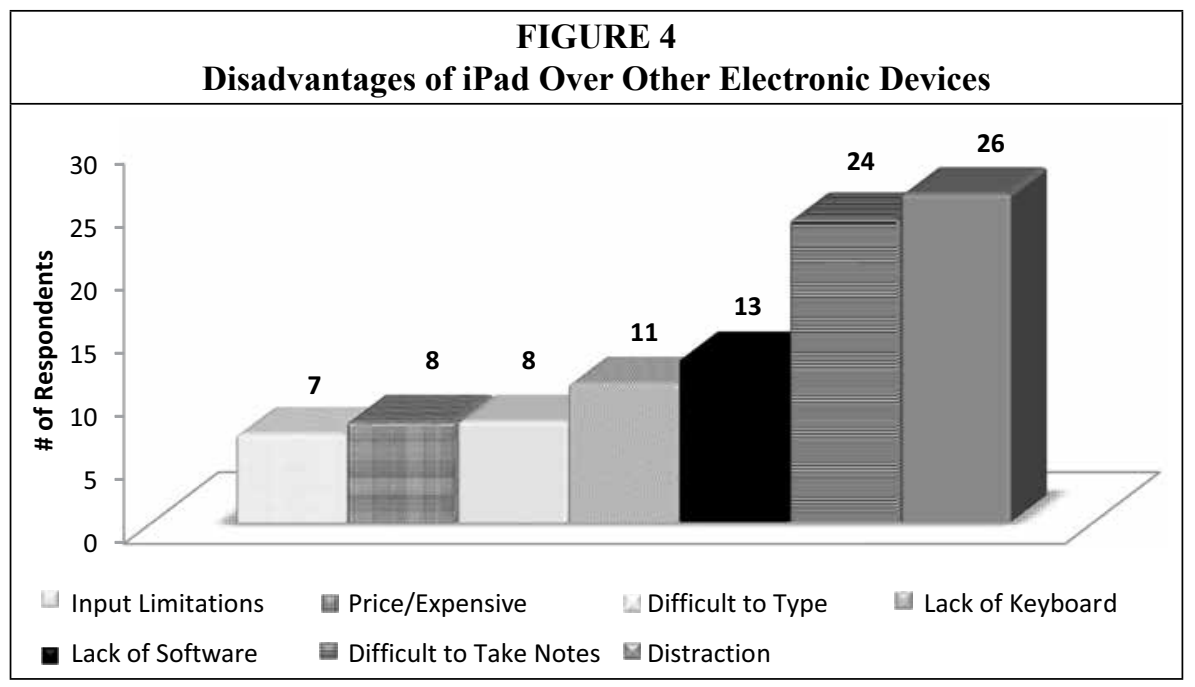




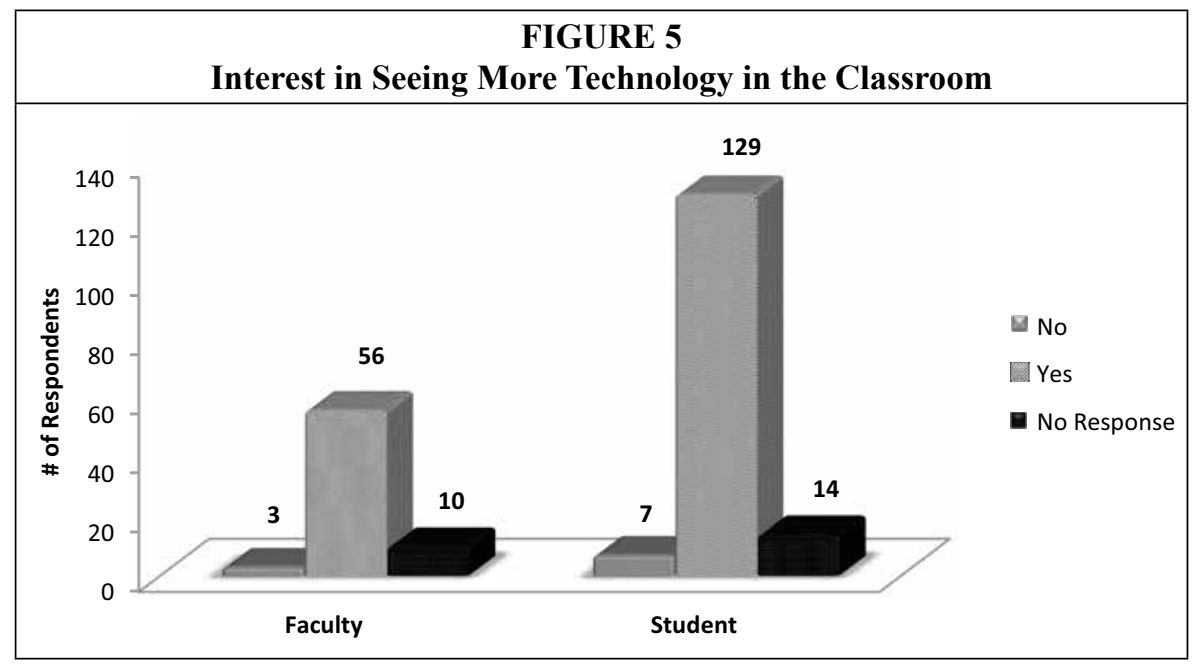

The disadvantage mentioned the most was the lack of keyboard. Other disadvantages mentioned by respondents included:

- The iPad's keypad takes some getting used to - and users were hesitant to rely on their typing abilities using the capacitive touchscreen when taking notes

- Lack of input limitations - there is no USB outlet, no CD slot-no easy way to transfer files from the iPad to traditional computing devices

- $\quad$ Price or expense was another disadvantage respondents saw over other electronic devices

Listed below are comments from the respondents about the disadvantages:

- "Cost, as it doesn't quite replace a laptop yet."

- "The touchscreen typing, rather than a keyboard."

- "The word processor isn't as advanced as a normal computer."

- "In a classroom, the only practical disadvantages would be more powerful, intensive tasks."

- "Lots of redundancies in terms of functionality."

- "Being distracted in class would be a disadvantage. Having the [I]nternet and applications at your fingers might distract you from paying attention."

- "Typing on the screen is more difficult than it is to type on a laptop and it is difficult to download things not from Apple. And several classes use online homework which is flash based."

- "It requires you to look down towards the screen, whereas on a netbook and laptop the screen is in the same direction as the lecturer."

- "Limited number of software programs."

- "Expensive! And hard to type on if you don't have the external keyboard. No USB."

In addition to gauging the use of the iPad in academia, the survey posed the concept of the need for technology in the classroom. There were 185 survey respondents interested in seeing more technology in the classroom.

Survey respondents were clear in their beliefs that, to use the devices to their full potential, implementing infrastructure requirements into academic budgets is a necessity.

When asked what steps are necessary to make technology a reality in the classroom, respondents answered with the following information from figure 6 . 


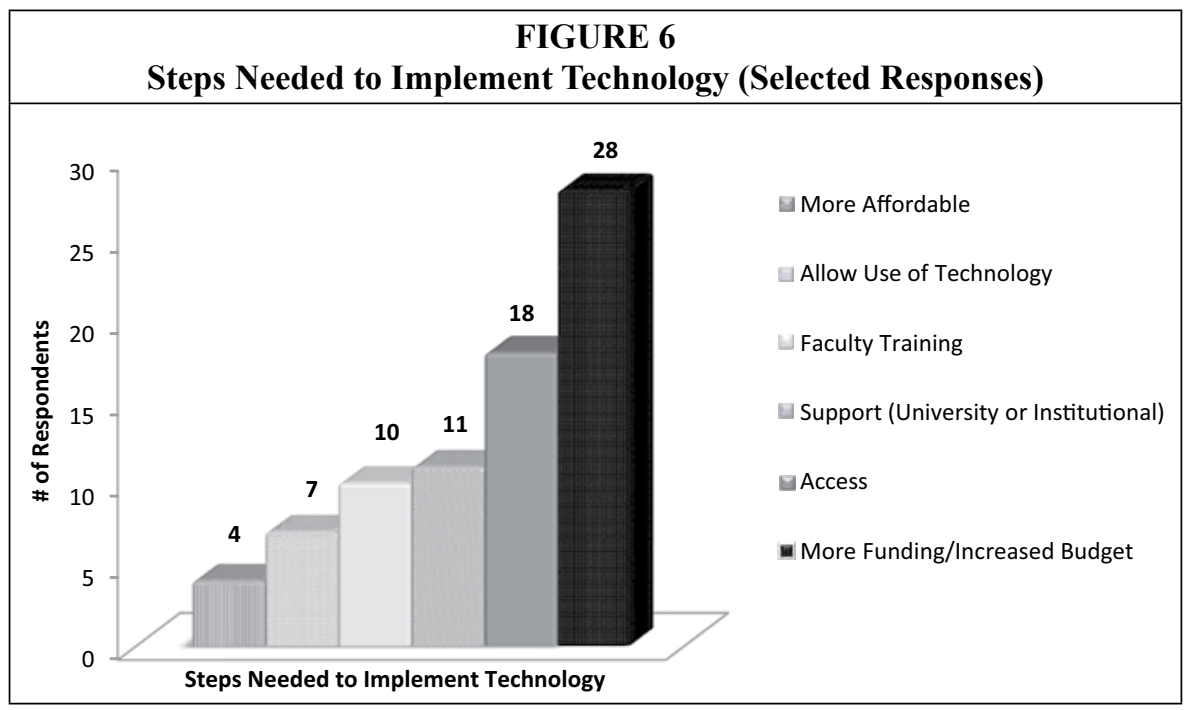

Survey respondents could list steps that they thought necessary to implement technology-but the researchers found that this question confused participants. With only 78 participants listing simple solutions to this broader problem, many respondents skipped this question.

For those who had used the iPad at the time of the survey, when asked what they use the most, answers included:

- Music

- Games

- Note taking
- Web browsing

- eBooks

- Internet

- E-mail

- Apps

The researchers posed the question to find out whether or not students and faculty use the iPad for entertainment purposes or for their coursework. Not all of the applications in use were for educational purposes; several applications in use were for entertainment value and personal management.

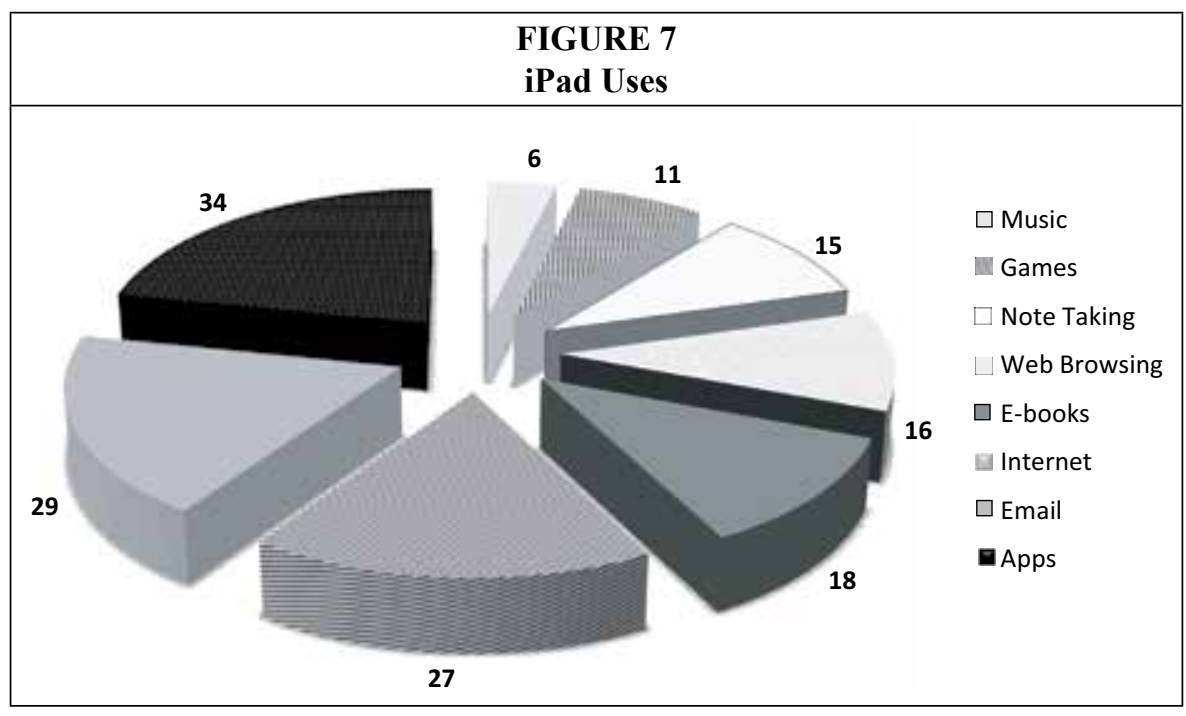




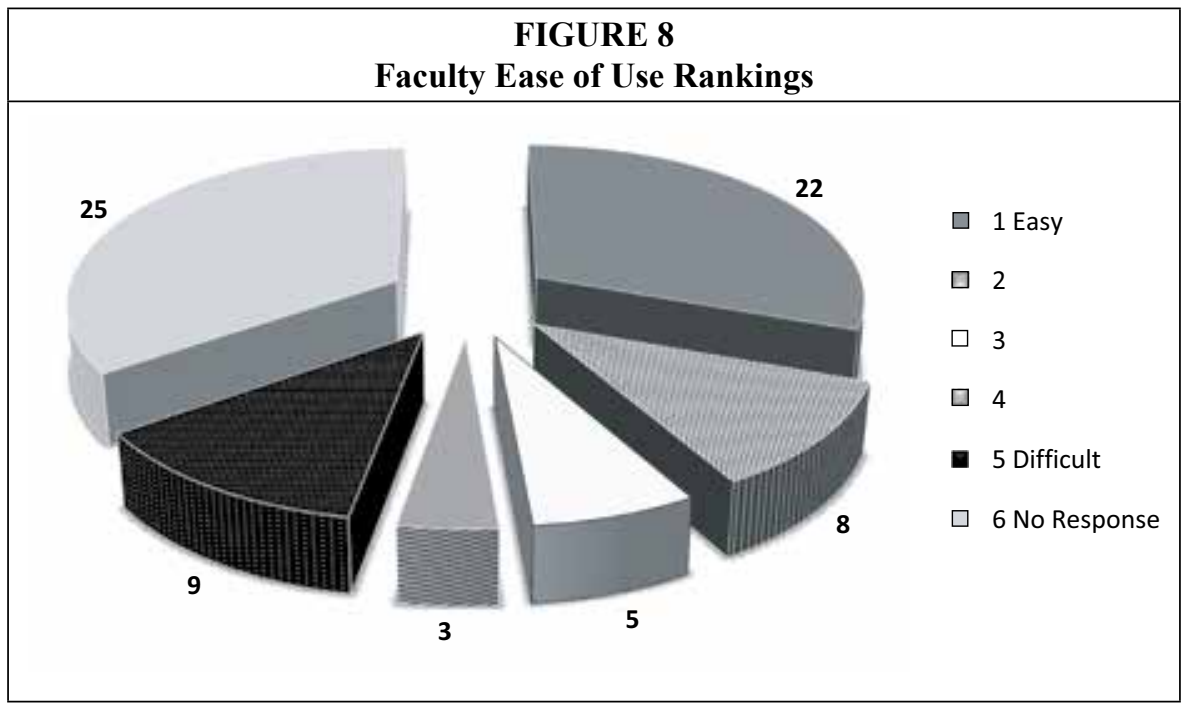

When respondents described how easy it is to use the functions mentioned in table 7, overall ease-of-use rankings for the iPad were as follows:

By comparing tables 8 and 9, both faculty and students described the overall ease of use as easy. However, the interesting part to note is that the faculty have an increase in the difficult range for the overall ease of use, whereas the students do not. This seems to be an indicator that supports the literature reviewed, as faculty may need to have training and additional support personnel to feel comfortable with using new technology in the classroom.
Overall, the survey suggests overwhelmingly that the iPad is a suitable device for use in the classroom for both students and professors. Though the iPad has become ubiquitous since the time that this research was conducted, its use in the classroom and in academia is still being studied.

\section{Focus Group}

The focus group discussions were lively at times, and the participants were eager to speak about their interactions with the device. Many of the novice users seemed to be on a fact-finding mission.

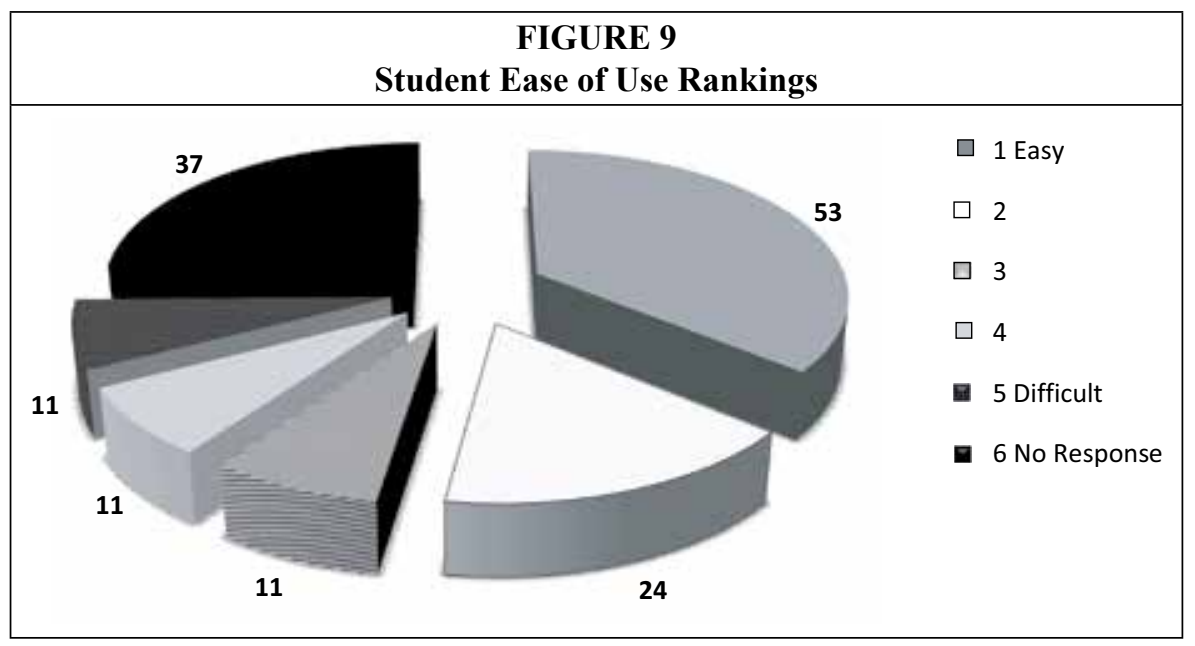


The participants were asking questions about the device and comparing the iPad to tablet PCs, laptops, or netbooks. Some were convinced that they would make the switch to the iPad, while others (fewer so) were going to remain with their device of choice. In contrast, the experienced users of the iPad seemed to enjoy swapping apps and talking about the advantages and disadvantages of the device.

Most of the participants appreciated the battery life, portability, and ease of use that the iPad possesses. They found it much better for "on the go" activities and found it to be much easier to use than a laptop, which may require carrying extras like a battery pack or mouse. They like the reader applications, which would allow them to load their textbooks onto the iPad, thus relieving the need to carry books around in a heavy backpack. Participants also valued the functionality of the iPad. It could be a tool for research, an entertainment piece, a note taker, a TV, and many other multiple uses.

During the focus groups, participants mentioned some specific uses for the iPad in academia. One participant noted the fact that the iPad can be used anywhere. This participant used the device while teaching in a patient setting to work on clinical notes with student counselors. As this participant often checked clinical notes while outside the office, she could review the student counselors' notes in real time, quickly offering comments and suggestions. It was discussed how this would be almost impossible before this technology.

Overwhelmingly, the focus groups disliked the capacitive touch keyboard. They found it difficult to use. However, several of the expert users found that, over time, the keypad became familiar and they became proficient at using it, or they compromised by buying an external keyboard. The complaint that seemed almost as prevalent as the keyboard was that there were no options for input devices, or no USB ports. However, it should be noted, and was brought up in the focus groups, that the iPad relies heavily on cloud computing; the producers probably felt that input devices would not be needed or used. Finally, one of the major complaints or dislikes of the iPad was the fact that it did not use or would not run any item on the Internet that required a flash plug-in. At the time of this study, though, application producers and many websites have already begun to build workarounds to compensate for the "flash problem." For example, the use of markup language HTML5 provides one solution to this problem.

Expert users found the iPad to be the answer to their technical glitches, solving a myriad of problems. They gave the groups many types of applications for different scenarios. There was discussion of planners, calendars, note taking, eReaders with several application names mentioned for each type of use. One expert user championed the ability of some apps to synchronize the data with several devices, which allowed his household and him to create a single grocery list that would update on all linked devices. On the other hand, many members of the focus groups gave the device a poor rating for the ever-growing list of applications. Another negative to the device is the skyrocketing price tag due to the addons, such as keyboards, and other plug-in equipment. This limits how the device can be used, as many were surprised that it took an add-on to display the iPad screen through a projector in the classroom. To some of the focus group participants, this makes the initial cost a little bit deceiving.

The researchers concluded that faculty and students are adapting to this new technology for personal use but are still trying to navigate the use in regard to research, teaching, and learning. Many are using the basic functions for research such as note taking or reading research on the device, but the researchers realize that there is an expanse of unexplored interactive terrain. Students and faculty alike can see the potential benefits. However, there are still matters that need to be addressed 
on several levels. If academia really wants faculty to use new technology, then faculty need help with training or awareness on the best ways to incorporate technology like the iPad into their teaching and learning. It is necessary for faculty to feel as comfortable with this technology as the students. To incorporate technology, classrooms will need updating. A stable infrastructure needs to be in place on campuses to allow these new devices to work properly; having Wi-Fi functionality on the device only to find that the campus Wi-Fi is not robust enough to allow that Wi-Fi functionality is a problem. As higher education addresses these issues, more and more faculty and students will continue to explore the developing new technology.

\section{Conclusion}

The Texas Tech University Libraries is a leader in providing innovative technology for its patrons. To retain this leadership role, research on the newest innovative technologies is necessary. With the goal of creating a better understanding of how tools and methods can assist in conducting better research and learning practices, the researchers were interested in how tablet PCs, specifically the iPad, would change the higher educational landscape. By developing a study to track the perceived effect from students and faculty; obtaining an internal grant to acquire seven iPads; and talking to students and faculty through surveys and focus groups, the researchers were able to gather preliminary data on how such technology may function in educational settings. The researchers have added to the increasing amount of information available for others to determine the potential technological uses in academia. The Texas Tech researchers have already incorporated iPad technology into their teaching, research, and daily use. After the completion of this study, the librarians were able to keep the iPads for dayto-day use. Several have almost replaced their laptops with the iPad. With heavy emphasis on outreach, they use the devices during database demonstrations for students, various campus and professional meetings, and visits to various colleges and departments. There is a good indication that, with the administration's understanding the need for support, the university will continue to grow and foster the infrastructure necessary to sustain the booming technological needs of higher education. With upcoming newer generations of iPads, the possibilities of its uses are endless.

\section{Notes}

1. John Thompson, "Is education 1.0 ready for web 2.0 students?" (2007), available online at www.innovateonline.info/pdf/vol3_issue4/Is_Education_1.0_Ready_for_Web_2.0_Students_.pdf [accessed 23 May 2011].

2. Ibid., 4-5.

3. Ibid., 3.

4. Oklahoma State University iPad Study, available online at http://news.okstate.edu/pressreleases/929-ipad-study-released-by-oklahoma-state-university [accessed 23 May 2011].

5. J. Fons, "A Year without Paper: Tablet Computers in the Classroom," Physics Teacher 48, no. 7 (2010): 481-83.

6. Elizabeth "Betty" Marcoux, “Technology and YOU,” Teacher Librarian 38, no. 5 (2011): 66; Professional Development Collection, EBSCOhost, available online at http://connection.ebscohost. com/c/articles/62570046/technology-you [accessed 28 July 2011].

7. R. van Oostveen, William Muirhead, William M. Goodman, "Tablet PCs and Reconceptualizing Learning with Technology: A Case Study in Higher Education," Interactive Technology and Smart Education 8, no. (2011) 2: 78-93.

8. Ibid., 80 .

9. Ibid., 81.

10. Ibid., 89 .

11. Ibid., 82. 
12. Amelito G. Enriquez, "Enhancing Student Performance Using Tablet Computers," College Teaching 58, no. 3 (2010): 77-84.

13. Ibid., 84 .

14. Ibid., 84 .

15. Mark Hawkes and Claver Hategekimana, "Impacts of Mobile Computing on Student Learning in the University: A Comparison of Course Assessment Data," Journal of Educational Technology Systems 38, no. 1 (2009): 63-74.

16. Ibid., 64.

17. Daniel Fusch, "Piloting the iPad," available online at www.academicimpressions.com/ news/piloting-ipad [accessed 6 January 2012].

18. Ibid.

19. Ibid.

20. Dian Schaffhauser, "Is the iPad Ready to Replace the Printed Textbook?" Campus Technology, available online at http://campustechnology.com/articles/2011/06/15/is-the-ipad-ready-to-replacethe-printed-textbook.aspx [accessed 2 August 2011].

21. David Nagel, "LIU Brooklyn Campus Extends iPad Program," Campus Technology, available online at http://campustechnology.com/articles/2010/10/04/liu-brooklyn-campus-extends-ipadprogram.aspx [accessed 3 March 2011].

22. Schaffauser, "Is the iPad Ready to Replace the Printed Textbook?"

23. Trina Marmarelli and Martin Ringle, "The Reed College iPad Study," available online at www.reed.edu/cis/about/ipad_pilot/Faculty_iPad_Reports_April2011.pdf [accessed 6 January 2012].

24. Ibid., 1 .

25. Ibid., 1.

26. Ibid., 3.

27. Dian Schaffhauser, "iPad Pilots at U Houston and CDI College Take Off," Campus Technology, available online at http://campustechnology.com/articles/2010/12/08/ipad-pilots-at-u-houstonand-cdi-college-take-off.aspx [accessed 3 March 2011]. 